\title{
Effects of Long-Term Walking on Baropodometric Parameters and Manual Muscle Strength
}

Rezende J M*, Vitorino PVO $^{2}$, Silva $\mathrm{AA}^{2}$, Pereira $\mathrm{EN}^{2}$, Lemos $\mathrm{TV}^{3}$, Sousa ALL ${ }^{4}$, J ardim $\mathrm{PCB}^{4}$, $\mathrm{J}$ ardim TSV ${ }^{4}$ and Barroso $\mathrm{WKS}^{4}$

${ }^{1}$ Post-Graduate Program in Health Sciences, Universidade Federal de Goiás, Goiânia-Goiás, Brazil

${ }^{2}$ School of Social and Health Sciences, Pontifícia

Universidade Católica de Goiás, Goiânia-Goiás, Brazil ${ }^{3}$ Physiotherapy Course, Universidade Estadual de Goiás, Goiânia-Goiás, Brazil

${ }^{4}$ Arterial Hypertension League, Universidade Federal de Goiás, Goiânia-Goiás, Brazil

*Corresponding author: Rezende J M, Programa de Pós-Graduação em Ciências da Saúde, Universidade Federal de Goiás, Avenida Marechal Rondon, apt 123 torre 2, Bairro: São Luis Residencial Brisas do Parque, CEP 74.563-355, Goiânia-Goiás, Brazil

Received: March 28, 2017; Accepted: April 21, 2017; Published: April 28, 2017

\begin{abstract}
Objectives: Assess the static baropodometric parameters and manual muscle strength before and during five days of long-distance walking.

Methods: Longitudinal study that assessed 25 male participants. Five assessments were made: baseline 20 days before the event $(\mathrm{A} 0)$ and the remainder (A1, A2, A3 and A4) during the walk at the end of each day. For the assessment, a baropodometer and the hydraulic manual dynamometer.

Results: The participants' average age was $45.6 \pm 9.1$ years and the mean body mass index $23.1 \pm 2.6 \mathrm{~kg} / \mathrm{m}^{2}$. The assessment included 250 feet: 204 neutral and 46 hollow. The maximum pressure in the right feet increased between A1 and A4 $(p=0.025)$ and dropped between $A 2$ and $A 3(p=0.051)$. The contact surface of the right feet decreased between $A 0$ and $A 1(p<0.001)$; increased between $A 1$ and $A 2(p=0.001)$ and decreased between $A 2$ and $A 3(p<0.001)$. The contact surface of the left feet decreased between $A 0$ and $A 1(p=0.001)$ increased between $A 1$ and $A 2(p<0.001)$ and between $A 1$ and $A 4(p=0.002)$. The right anteroposterior core strength increased between $A 0$ and $A 3(p=0.001)$ and between $A 0$ and $A 4(p=0.009)$; on the left side, it increased between $A 0$ and $A 2$ $(p=0.043), A 0$ and $A 3(p=0.008)$ and $A 0$ and $A 4(p=0.001)$. The muscle strength did not change.
\end{abstract}

Conclusion: Most participants in the sample possessed neutral feet. The burden on the lower right limb increased, which may have been due to limb dominance and/or changes in the route relief and the distance walked.

Keywords: Aerobic Exercise; Muscle Strength Dynamometer; Physical Effort; Sports

\section{Introduction}

The assessment of plantar pressure distributions, the plantar surface and muscle strength demonstrates the intensity of stress on the plantar arches during physical effort such as walking. Walking is considered to be a physical exercise practiced around the world and various studies have demonstrated its benefits. Nevertheless, until date, little information is available on the behavior of the feet and the muscle strength during long-term walks. Hence, this is the first study to assess the baropodometric variables and manual muscle strength during a long-term walk.

The Goiás Ecological Walk is an annual event in which preselected adults and elderly participate. The participants walk during some parts and run slowly during others. Therefore, it can be characterized as a medium to high-intensity long-term exercise.

During any kind of exercise in the orthostatic position, the foot is the only body part that has contact with the ground. Its structure has been organized to bear the body weight, promote damping, help to maintain the balance and enhance thrust, elasticity and flexibility to walk, jump and run [1]. Therefore, an appropriate static posture in athletes, conditioned by good foot support on the floor, offers appropriate joint dynamics and harmonic movements with less energy consumption [2].
Variations in the foot posture, such as flat feet (reduction of longitudinal arch) or hollow feet (increased arch) are considered an intrinsic risk factor of injury due to the inappropriate lower limb movement [3]. The biomechanical study of walking and running favors the understanding about the structure, function, capacity of the lower limbs and of the global kinetic chain that allows a human being to walk and/or run [4].

To assess foot dysfunctions, baropodometry is used as an instrument, which is an investigation to map the plantar pressure, the foot's contact surface with the ground, as well as to register the reaction strengths of the ground during static and dynamic postures. Therefore, this method is very important to understand the appropriate orthostatic position or the position that can result from an incorrect postural adaptation or secondary to certain conditions that affect or may be affected by the posture $[5,6]$.

Another important aspect to analyze the functional performance of athletes is the assessment of the muscle strength, which can be influenced by internal and external elements. Among the internal elements, the following stand out: the transverse section of the muscle fiber, number of muscle fibers, coordination, muscle fiber contraction speed, type of muscle fiber and age. The external elements include: time of day, training method, motivation, nutrition. The upper limb muscle strength assessed by the manual dynamometer is a modality
J Fam Med - Volume 4 Issue 3 - 2017

ISSN : 2380-0658 | www.austinpublishing group.com

Rezende et al. (C) All rights are reserved
Citation: Rezende JM, Vitorino PVO, Silva AA, Pereira EN, Lemos TV, Sousa ALL, et al. Effects of Long-Term Walking on Baropodometric Parameters and Manual Muscle Strength. J Fam Med. 2017; 4(3): 1116 
Table 1: Distance walked and daily speed, minimum and maximum temperature, track relief and stay on the same side of the track in kilometers during the ecological walk.

\begin{tabular}{|c|c|c|c|c|c|c|}
\hline Day & Distance walked & Average speed & Minimum temp. & Maximum temp. & Track relief & Staying on the same side of the track \\
\hline 15-Jul & $70 \mathrm{~km}$ & $7.0 \mathrm{~km} / \mathrm{h}$ & $21^{\circ}$ & $37^{\circ}$ & Predominantly uphill & $\begin{array}{l}43 \mathrm{~km} \text { on Right } \\
27 \mathrm{~km} \text { on Left }\end{array}$ \\
\hline 16-Jul & $59 \mathrm{~km}$ & $6.8 \mathrm{~km} / \mathrm{h}$ & $19^{\circ}$ & $31^{\circ}$ & Predominantly downhill & $\begin{array}{c}40 \mathrm{~km} \text { on Right } \\
19 \mathrm{~km} \text { on Left }\end{array}$ \\
\hline 17-Jul & $67 \mathrm{~km}$ & $7.7 \mathrm{~km} / \mathrm{h}$ & $22^{\circ}$ & $38^{\circ}$ & Predominantly uphill & $\begin{array}{l}42 \mathrm{~km} \text { on Right } \\
25 \mathrm{~km} \text { on Left }\end{array}$ \\
\hline 18-Jul & $55 \mathrm{~km}$ & $8.5 \mathrm{~km} / \mathrm{h}$ & $18^{\circ}$ & $42^{\circ}$ & Predominantly level & $\begin{array}{c}39 \mathrm{~km} \text { on Right } \\
16 \mathrm{~km} \text { on Left }\end{array}$ \\
\hline
\end{tabular}

that demonstrably assesses the global muscle strength [7].

The muscle strength is considered an important physical aptitude variable that can be related to health as well as physical performance in different exercise modalities. Thus, we know that the strength disequilibria can act on the joints, causing postural or biomechanical joint alterations and, consequently, predispose to the appearance of injuries or even interfere through low performance levels [8].

No studies have been developed that assess the baropodometric components and muscle strength of participants in the Ecological Walk, which is a unique event in the world. To offer better conditions to the participants in the Ecological Walk, this study was developed to assess the baropodometric parameters and muscle strength of participants in a long-term activity. Thus, the objectives in this study were to describe the foot types, lower limb dominance, to compare the arch index and the baropodometric assessment and manual muscle strength measures before and in between the days of the Ecological Walk.

\section{Methods}

Longitudinal study that assessed male participants in the Goiás Ecological Walk. All participants read and signed the Free and Informed Consent Form. This study received approval from the Ethics Committee at Pontifícia Universidade Católica de Goiás under protocol CAAE: 29430114.8.0000.0037/2014.

The following variables were assessed: plantar pressure, baropodometric data, lower limb dominance, arch index and manual muscle strength.

The data collection consisted of five moments: a baseline assessment (A0) that took place 20 days before the event, and four other assessments (A1, A2, A3 and A4) on the days of the event, always at the end of each day. The final day of the walk was excluded due to the logistics of the event site, making the data collection difficult.

To assess the plantar pressure and baropodometric data, a footwork 3.7.6.0 baropodometer was used. Each participant stayed immobile, standing comfortably on both feet, during 20 seconds, looking at the horizon, arms along the body, without any weight in their pockets or any type of movement during the assessment [8]. The participant always adopted the same posture throughout the analysis.

The lower limb dominance was assessed by means of the Waterloo Footedness Questionnaire - Revised (Attachment B). To calculate the arch index, the measures were based on the maximum plantar pressure print, given by the baropodometric results: from the second metatarsal until the heel base, the longitudinal line (L line) was obtained. The value of line $\mathrm{A}$ is found at the midpoint of the $\mathrm{L}$ line and the value of line $B$ at $1 / 6$ of the $L$ line. The index is calculated by dividing line A by line B. Values between 0.3 and 1.0 were considered as neutral feet; values superior to 1.0 as flat feet and values inferior to 0.3 as hollow feet [9]. The arch index was calculated in all assessments from A0 until A4, considering the five data collection moments, on the right and left side, totaling the sample of 250 feet.

The manual grip muscle strength was measured using an SH 5001 hydraulic hand dynamometer. The participant remained seated on a chair without armrests, with the feet fully resting on the floor, the hips against the backrest of the chair and the knees bent at $90^{\circ}$. The arms remained parallel to the body, shoulders forward, elbows flexed at $90^{\circ}$ and forearm in the neutral position, wrist extended between $0^{\circ}$ and $30^{\circ}$ and $0^{\circ}$ to $15^{\circ}$ of ulnar deviation and the fingers semi-flexed [7]. The palmar pressure was measured three consecutive times, with a minimum interval of one minute to avoid muscle fatigue. All measures were taken on a single occasion, always by the same examiner, using a manual grip dynamometer (SH 5001). The muscle strength measure used for the analysis was the average of the three measures in $\mathrm{Kg} / \mathrm{f}$.

The temperature during the walk was measured using an Incoterm (7424.02.0.00) digital thermometer. The mean route speed was calculated by the index between the distance and the time. To determine the relief, resources from Google maps elevation for route were used, which provides the distance run in kilometers $(\mathrm{Km})$ with the hills and slopes.

The data were analyzed using the Statistical Package for the Social Sciences (SPSS), version 20.0. For the quantitative variables, the mean and standard deviation were used. The data distribution was verified using the Shapiro-Wilk test. The comparisons between the measures at rest and the walking days concerning the muscle strength and the plantar pressure were established using ANOVA for repeated measures, followed by Bonferroni's post hoc test. Significance was set as $\mathrm{p}<0.05$.

\section{Results}

This event took place in July 2014 and covered a distance of $308 \mathrm{~km}$, during five day, with a daily average of $62 \mathrm{~km}$. The mean temperature along the way was $30^{\circ}$, ranging between $18^{\circ}$ and $42^{\circ}$. The mean walking speed across all days was $7.6 \mathrm{~km} / \mathrm{h}$. Along the way, the participants remained most of the distance (207 kilometers; $67.2 \%$ of the distance) on the right of the track. During two days, uphill stretches were predominant; during two other days, downhill stretches and, on one day, the relief was predominantly level (Table 1). 


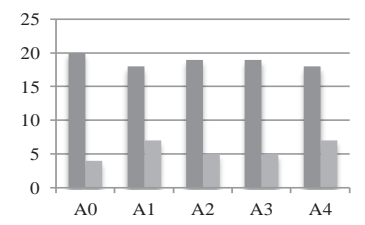

A: Left feet

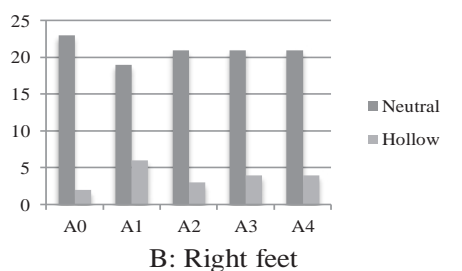

B: Right teet
Figure 1: Distribution of foot types according to calculation of arch index n=25, Goiânia, 2014.

The sample consisted of 25 male participants with a mean age of $45.6 \pm 9.1$ years (minimum 29 and maximum 62 years) and mean body mass index (BMI) of $23.1 \pm 2.6 \mathrm{~kg} / \mathrm{m}^{2}$. All participants exercised before the Ecological Walk, 92.0\% (23) aerobic exercise and only 8.0\% (2) practiced aerobic and resistance exercises. Among the participants, 20 presented right lower limb dominance, two left lower limb dominance, two frequently equal dominance in both limbs and one did not answer the questionnaire.

In the baropodometric tests, five measures were taken of the 25 participants' both feet (right and left), totaling 50 feet per day and 250 at the end of the five assessments. The findings showed 204 neutral feet and 46 hollow feet according to the arch index. No flat feet were found in the sample assessed (Figure 1).

For the right and left feet, the plantar surface, anteroposterior core strength and forefoot and rear foot mass division varied. The maximum pressure and laterolateral core strength also varied in the right feet only (Table 2).

The maximum pressure in the right feet increased between $A 1$ and A4 $(\mathrm{p}=0.025)$. The left feet presented no significant change in the maximum pressure. The contact surface of the right feet decreased between $A 0$ and A1 $(p<0.001)$; increased between $A 1$ and A2 $(\mathrm{p}=0.001)$ and decreased between $\mathrm{A} 2$ and $\mathrm{A} 3(\mathrm{p}<0.001)$. In the left feet, the contact surface presented the following significant variations: reduction between $\mathrm{A} 0$ and $\mathrm{A} 1$ ( $\mathrm{p}=0.001)$; increase between $\mathrm{A} 1$ and $\mathrm{A} 2$ $(\mathrm{p}<0.001)$ and between A1 and A4 ( $\mathrm{p}=0.002)$ (Figure 2).

The right anteroposterior core strength increased between A0 and $\mathrm{A} 3(\mathrm{p}=0.001)$ and between $\mathrm{A} 0$ and $\mathrm{A} 4(\mathrm{p}=0.009)$; on the left, it increased between A0 and A2 ( $\mathrm{p}=0.043), \mathrm{A} 0$ and $33(\mathrm{p}=0.008)$ and between $A 0$ and $A 4(p=0.001)$. The right laterolateral core strength increased between A0 and A3 ( $\mathrm{p}=0.004)$. The left laterolateral core strength and the right and left mass divisions presented no significant variations (Figure 3).

The comparisons among the assessment days regarding muscle strength in the right $(\mathrm{p}=0.723)$ and left $(\mathrm{p}=0.723)$ upper limb showed no changes. The baseline muscle strength was $42.6 \pm 1.3 \mathrm{Kgf}$ for both limbs.

\section{Discussion}

These study results show that most athletes' feet were neutral. The plantar arches of the participants' feet changed between the baseline assessments and the assessments during the walk, possibly influenced by the effort and relief. After the exercise, the feet became hollower, followed by accommodation. In a study that assessed the effects of running-induced fatigue on the plantar pressure distribution of 42
Table 2: Distribution of variables: maximum pressure, contact surface, core strength and right and left foot mass division of participants in ecological walk, n 25 , Goiás, 2014.

\begin{tabular}{|c|c|c|c|c|c|c|}
\hline \multirow{2}{*}{ Variables } & Mean/SD & $95 \% \mathrm{Cl}$ & $\mathbf{p}$ & Mean/SD & $95 \% \mathrm{Cl}$ & $\mathbf{p}$ \\
\hline & Right & Right & Right & Left & Left & Left \\
\hline \multicolumn{7}{|c|}{ Maximum pressure $\left(\mathrm{Kgf} / \mathrm{cm}^{2}\right)$} \\
\hline AO & $141.1 \pm 5.5$ & 129.7-152.6 & \multirow{5}{*}{$p<0.01$} & $167.7 \pm 9.5$ & 148.0-187.4 & \multirow{5}{*}{$p=0.55$} \\
\hline A1 & $137.6 \pm 5.6$ & 125.8-149.3 & & $156.2 \pm 9.7$ & 136.1-176.4 & \\
\hline A2 & $145.6 \pm 8.2$ & 128.6-162.5 & & $161.8 \pm 8.6$ & 144.0-179.6 & \\
\hline A3 & $133.6 \pm 8.6$ & 115.8-151.4 & & $155.1 \pm 10.0$ & 134.4-175.8 & \\
\hline A4 & $159.4 \pm 7.1$ & $144.5-174.2$ & & $161.3 \pm 9.1$ & 142.3-180.2 & \\
\hline \multicolumn{7}{|c|}{ Surface $\left(\mathrm{cm}^{2}\right)$} \\
\hline AO & $141.1 \pm 5.5$ & 129.6-152.6 & \multirow{5}{*}{$p=0.02$} & $109.2 \pm 3.2$ & 102.3-115.7 & \multirow{5}{*}{$p=0.05$} \\
\hline A1 & $137.6 \pm 5.6$ & $125.8-149.3$ & & $100.0 \pm 2.9$ & 93.2-108.3 & \\
\hline A2 & $145.6 \pm 8.2$ & 128.6-162.5 & & $109.7 \pm 2.7$ & 102.2-117.7 & \\
\hline A3 & $133.6 \pm 8.6$ & 115.8-151.4 & & $101.8 \pm 5.1$ & 91.8-115.0 & \\
\hline A4 & $159.4 \pm 7.1$ & $144.5-174.2$ & & $111.0 \pm 3.1$ & 102.6-117.8 & \\
\hline \multicolumn{7}{|c|}{ Anteroposterior core strength $\left(\mathrm{cm}^{2}\right)$} \\
\hline A0 & $1.3 \pm 0.0$ & $1.1-1.5$ & \multirow{5}{*}{$p=0.01$} & $1.3 \pm 0.1$ & $1.0-1.6$ & \multirow{5}{*}{$p=0.01$} \\
\hline A1 & $2.4 \pm 0.3$ & $1.7-3.2$ & & $2.9 \pm 0.6$ & $1.5-4.2$ & \\
\hline A2 & $2.0 \pm 0.2$ & $1.5-2.4$ & & $2.0 \pm 0.1$ & $1.6-2.4$ & \\
\hline A3 & $2.3 \pm 0.2$ & $1.8-2.9$ & & $2.0 \pm 0.1$ & $1.6-2.3$ & \\
\hline A4 & $2.6 \pm 0.3$ & $2.0-3.3$ & & $2.6 \pm 0.21$ & $2.1-3.2$ & \\
\hline \multicolumn{7}{|c|}{ Laterolateral core strength $\left(\mathrm{cm}^{2}\right)$} \\
\hline AO & $0.2 \pm 0.0$ & $0.0-0.4$ & \multirow{5}{*}{$p=0.04$} & $0.1 \pm 0.0$ & $0.0-0.2$ & \multirow{5}{*}{$p=0.33$} \\
\hline A1 & $0.7 \pm 0.1$ & $0.3-1.0$ & & $0.9 \pm 0.5$ & $0.2-2.0$ & \\
\hline A2 & $0.3 \pm 0.1$ & $0.1-0.5$ & & $0.3 \pm 0.1$ & $0.1-0.5$ & \\
\hline A3 & $0.5 \pm 0.1$ & $0.2-0.8$ & & $1.8 \pm 1.5$ & 4.1-2.7 & \\
\hline A4 & $0.3 \pm 0.1$ & $0.1-0.5$ & & $0.5 \pm 0.1$ & $0.2-0.7$ & \\
\hline \multicolumn{7}{|c|}{ Forefoot mass division (\%) } \\
\hline AO & $55.4 \pm 2.0$ & $51.0-59.7$ & \multirow{5}{*}{$p=0.01$} & $49.9 \pm 2.2$ & $45.4-54.5$ & \multirow{5}{*}{$p=0.03$} \\
\hline A1 & $56.7 \pm 1.5$ & $47.8-56.1$ & & $50.7 \pm 1.8$ & $46.9-54.5$ & \\
\hline A2 & $58.0 \pm 2.1$ & $53.4-60.30$ & & $54.4 \pm 1.8$ & $50.6-58.1$ & \\
\hline A3 & $53.2 \pm 1.9$ & $53.6-62.4$ & & $53.3 \pm 1.7$ & $49.6-56.9$ & \\
\hline A4 & $52.0 \pm 2.0$ & $49.1-57.3$ & & $50.5 \pm 1.3$ & $47.6-53.4$ & \\
\hline \multicolumn{7}{|c|}{ Rearfoot mass division (\%) } \\
\hline AO & $48.0 \pm 2.0$ & $43.8-52.1$ & \multirow{5}{*}{$p=0.01$} & $50.0 \pm 2.2$ & $45.4-54.5$ & \multirow{5}{*}{$p=0.03$} \\
\hline A1 & $43.2 \pm 1.5$ & $39.9-46.5$ & & $49.2 \pm 1.8$ & $45.4-53.0$ & \\
\hline A2 & $41.9 \pm 2.1$ & $37.5-46.3$ & & $45.5 \pm 1.8$ & $41.8-49.3$ & \\
\hline A3 & $46.7 \pm 1.9$ & $42.6-50.8$ & & $46.6 \pm 1.7$ & $42.9-50.2$ & \\
\hline A4 & $44.5 \pm 2.0$ & $40.2-48.9$ & & $49.4 \pm 1.3$ & $46.6-52.3$ & \\
\hline
\end{tabular}

ANOVA for repeated measures.

novel runners (21 with hollow feet and 21 with flat feet), changes in plantar pressure were identified in both groups. This change can contribute to running injuries, as the fatigue moved the plantar pressure to the first three metatarsal bones and reduced it on the fourth and fifth for flat feet, while moving it to the side of the foot for hollow feet [10]. High injury rates in athletes with hollow feet are 

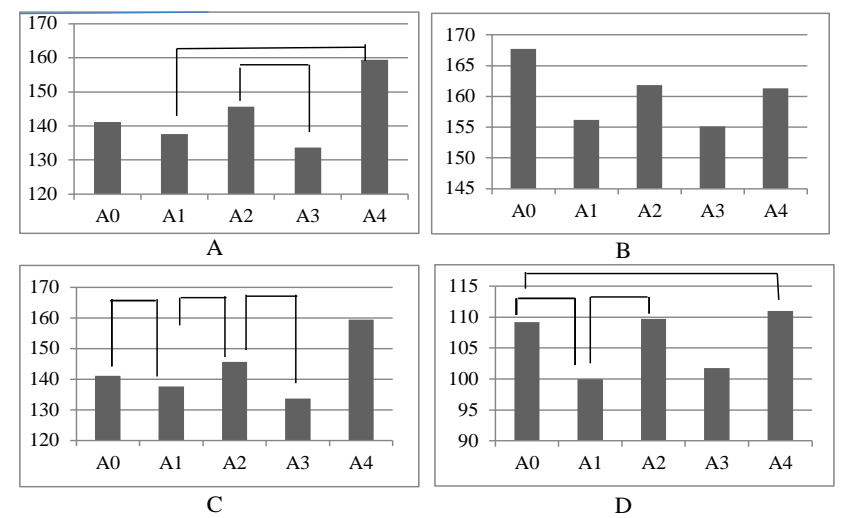

Figure 2: Right $(A)$ and left $(B)$ maximum pressure; right contact surface $(C)$ and left contact surface $(D)$ measures correspond to baseline $(A 0)$ and during walking days (A1, A2, A3, A4), $n=25,2014$.
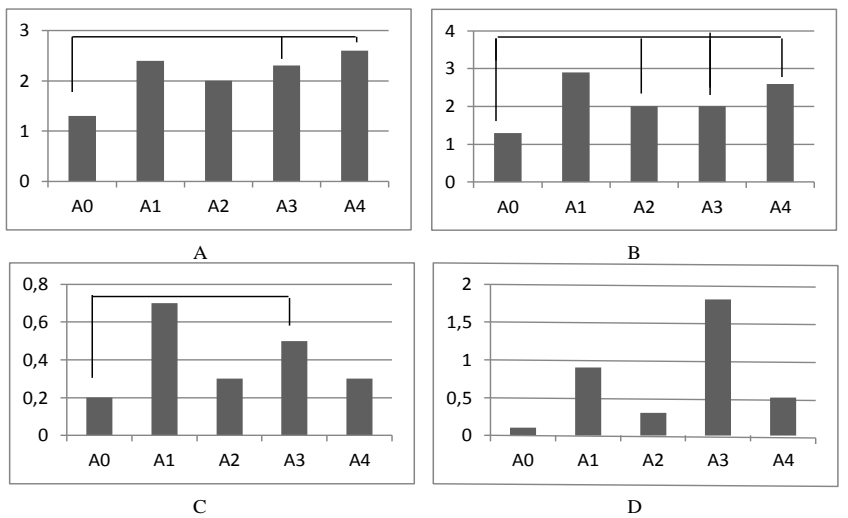

Figure 3: Comparative graphs of right (A) andleft (B) anteroposterior and laterolateral right $(C)$ andleft $(D)$ core strength variables at baseline $(A 0)$ and during walking days (A1, A2, A3, A4) n=25, 2014.

considered to be associated with increased plantar pressure burden [11].

In our study, we also identified a gradual increase in the plantar pressure in the right foot between the first and fourth day, except between the second and the third day. On the second day of the walk, the route was predominantly downhill, against predominantly uphill stretches on the third day. The pressure was higher during the downhill stretches as, when walking downhill, the braking movement provokes a greater discharge on the feet, increasing both the pressure and the contact surface [12]. Although this change is expected, orientations on the use of sneakers with appropriate buffering and strengthening of the synergist muscles in the braking movement are suitable for this population, with a view to postural adaptations and injury prevention.

The lower limb dominance was predominantly to the right and the plantar pressure was greater on the left (non-dominant) side. In a study that compared the biomechanical adaptation of running between the dominant and the non-dominant leg of 24 runners who ran 200 miles $(351 \mathrm{~km})$, it was identified that the hip and knee of the dominant leg presented a more extended position. This demonstrated that the dominant limb exercises greater strength, while the nondominant leg permits the stabilization needed to execute the movements [13].

In our findings, the behavior of the plantar surface throughout the walk was similar to the behavior of the plantar pressure. The plantar surface of both feet increased throughout the walk. The contact surface increases, especially in the middle of the feet, in a more enhanced manner in individuals with flat feet after the exercise, as the anatomic characteristics influence the distribution pattern of plantar pressure [14].

During the walk, the anteroposterior instability increased in the lower right and left limbs, and the laterolateral instability in the lower right limb. This oscillation indicates a change in the biomechanical gait, balance and body posture characteristics in the adaptation of the musculoskeletal system [15].

Our findings suggest that the long-term and high-intensity walk is not directly related with increased muscle strength. The skeletal muscles are unable to adapt metabolic and morphologically to both trainings simultaneously. The muscle adaptations observed in response to the strength training differ from the adaptations observed after aerobic resistance training (increased glycolytic enzymatic activity, white fiber hypertrophy, increased mitochondrial density, increased enzymatic activity). Resistance exercises are important for these participants as they reduce the risk of injuries [16] and promote improvements in the muscle strength, which is not evidenced by the practice of aerobic exercises.

Therefore, to enhance the functional performance of participants in the Ecological Walk and similar exercises, we recommend: specific training between the assessment of physical aptitude and the start of the event; undertaking of exercises with proprioceptive, static and dynamic balance stimuli, mainly for the muscles involving the ankle and foot joints; concomitant use of general resistance and plantar muscle exercises with plantar fascia stretching to reduce the accentuation of foot deviations for flat as well as hollow feet, respectively, thus improving the fall or rise of the plantar arch.

This study assessed the effects of the ecological walk only during the walk, without long-term monitoring to assess chronic effects. In addition, the baseline measures were taken one month before the events. Nevertheless, this is the first study to assess the baropodometric variables and muscle strength in these participants.

\section{Conclusion}

Most participants in the Ecological Walk presented neutral feet. The maximum pressure and surface of the right feet, which were identified as dominant for most participants, changed during the walk. These changes can derive from the relief during the walk and from the distance walked. Along the route, the relief was predominantly uphill, which can suggest changes in the behavior of the static baropodometric parameters, with a greater burden in the lower right limb and increased anteroposterior core strength. As observed, this sports modality was unable to acutely change the muscle strength, as expected from a predominantly aerobic activity.

\section{References}

1. Buldt AK, Murley GS, Butterworth P, Levinger P, Menz HB, Landorf KB. The Relationship Between Foot Posture and Lower Limb Kinematics During Walking: A Systematic Review. Gait \& posture. 2013; 38: 363-372. 
2. Ahn AN, Brayton C, Bhatia T, Martin P. Muscle Activity and Kinematics of Forefoot and Rearfoot Strike Runners. J Sport Health Sci. 2014; 3: 102-112.

3. Buldt AK, Levinger P, Murley GS, Menz HB, Nester CJ, Landorf KB. Foo Posture is Associated with Kinematics of the Foot During Gait: A Comparison of Normal, Planus and Cavus Feet. Gait \& posture. 2015; 42: 42-48.

4. Nicola TL, Jewison DJ. The Anatomy and Biomechanics of Running. Clinics in sports medicine. 2012; 31: 187-201.

5. Rosario JL. A Review of the Utilization of Baropodometry in Postural Assessment. Journal of bodywork and movement therapies. 2014; 18: 215 219 .

6. Fortaleza ACdS, Martinelli AR, Nozabieli AJL, Mantovani AM, Camargo MRd, Chagas EF, et al. Avaliação das Pressões Plantares em Diferentes Situações por Baropodometria. Colloquium Vittae. 2011; 3: 06-10.

7. Schlüssel MM, Anjos LA, Vasconcellos MT, Kac G. Reference Values of Handgrip Dynamometry of Healthy Adults: A Population-Based Study. Clin Nutr. 2008; 27: 601-607.

8. Garcia-Perez JA, Perez-Soriano P, Llana S, Martinez-Nova A, SanchezZuriaga D. Effect of Overground vs Treadmill Running on Plantar Pressure: Influence of Fatigue. Gait \& posture. 2013; 38: 929-933.

9. Ribeiro AP, Souza FT, Luner DH, Monte-Raso VV. Confiabilidade Inter e Intra-Examinador da Fotopodometria e Intra-Examinador da Fotopodoscopia. Rev Bras Fisioter. 2006; 10: 435-439.

10. Anbarian M, Esmaeili $H$. Effects of running-induced fatigue on plantar pressure distribution in novice runners with different foot types. Gait \& posture. 2016 ; 48: 52-56
11. Wegener C, Burns J, Penkala S. Effect of Neutral-Cushioned Running Shoes on Plantar Pressure Loading and Comfort in Athletes with Cavus Feet: A Crossover Randomized Controlled Trial. The American journal of sports medicine. 2008; 36: 2139-2146

12. Francis CA, Lenz AL, Lenhart RL, Thelen DG. The Modulation of Forward Propulsion, Vertical Support, and Center of Pressure by the Plantar flexors During Human Walking. Gait \& posture. 2013; 38: 993-997.

13. Kong PW, Candelaria NG, Smith D. Comparison of Longitudinal Biomechanical Adaptation to Shoe Degradation Between the Dominant and Non-Dominant Legs During Running. Human movement science. 2011; 30: 606-613.

14. Fu W, Fang Y, Liu DMS, Wang L, Ren S, Liu Y. Surface Effects on In-Shoe Plantar Pressure and Tibial Impact During Running. J Sport Health Sci. 2015; 4: 384-390.

15. Wong P, Chamari K, Chaouachi A, Mao W, Wisloff U, Hong Y. Difference in Plantar Pressure Between the Preferred and Non-Preferred Feet in Four Soccer-Related Movements. Br J Sports Med. 2007; 41: 84-92.

16. Baltich J, Emery CA, Stefanyshyn D, Nigg BM. The Effects of Isolated Ankle Strengthening and Functional Balance Training on Strength, Running Mechanics, Postural Control and Injury Prevention in Novice Runners: Design of a Randomized Controlled Trial. BMC musculoskeletal disorders 2014; 15: 407.
J Fam Med - Volume 4 Issue 3 - 2017

ISSN : 2380-0658 | www.austinpublishing group.com

Rezende et al. (@) All rights are reserved
Citation: Rezende JM, Vitorino PVO, Silva AA, Pereira EN, Lemos TV, Sousa ALL, et al. Effects of Long-Term Walking on Baropodometric Parameters and Manual Muscle Strength. J Fam Med. 2017; 4(3): 1116. 